\title{
A portable cell culture system with a simple microscope, oxygen sensor and MEA amplifier
}

See full paper @ https://ieeexplore.ieee.org/document/8288684

Dhanesh Kattipparambil Rajan, Joose Kreutzer, Hannu Välimäki, Mari Pekkanen-Mattila, Antti Ahola, Anne Skogberg, Katriina Aalto-Setälä, Heimo Ihalainen, Pasi Kallio, Jukka Lekkala

BioMediTech Institute and Faculty of Biomedical Sciences and Engineering, Tampere University, Finland

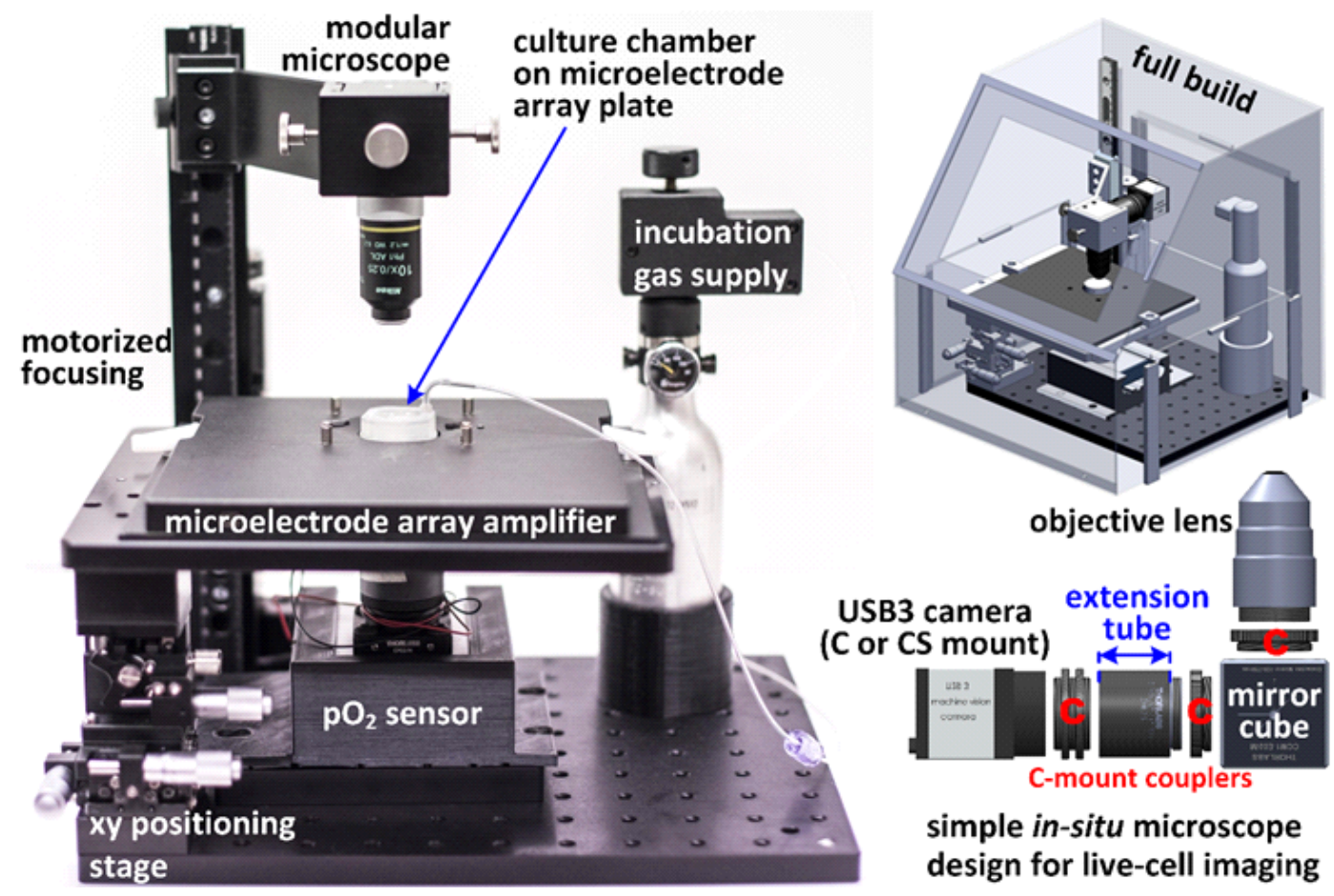

- Portable and customisable live-cell imagingsystem

- Modular invert-upright-convertible microscope

- PDM Smini-bioreactor for cell culturing

- Fuorescence-based oxygen sensor

- Bioelectric MEA signal amplifier

- Video based cardiomyocyte beatinganalysis

D. K. Rajan et al., "A Portable Live-Cell Imaging System With an Invert-Upright-Convertible Architecture and a MiniBioreactor for Long-Term Simultaneous Cell Imaging, Chemical Sensing, and Electrophysiological Recording," in IEEE Access, vol. 6, pp. 11063-11075, 2018. doi: 10.1109/ACCESS.2018.2804378 